\title{
Demonstration of an Electronic Gamma-Ray Spectrum Synthesizer
}

\author{
S.J. Luke
}

April 3, 2002

U.S. Department of Energy

Lawrence

Livermore

National

Laboratory 


\section{DISCLAIMER}

This document was prepared as an account of work sponsored by an agency of the United States Government. Neither the United States Government nor the University of California nor any of their employees, makes any warranty, express or implied, or assumes any legal liability or responsibility for the accuracy, completeness, or usefulness of any information, apparatus, product, or process disclosed, or represents that its use would not infringe privately owned rights. Reference herein to any specific commercial product, process, or service by trade name, trademark, manufacturer, or otherwise, does not necessarily constitute or imply its endorsement, recommendation, or favoring by the United States Government or the University of California. The views and opinions of authors expressed herein do not necessarily state or reflect those of the United States Government or the University of California, and shall not be used for advertising or product endorsement purposes.

This work was performed under the auspices of the U. S. Department of Energy by the University of California, Lawrence Livermore National Laboratory under Contract No. W-7405-Eng-48.

This report has been reproduced directly from the best available copy.

Available electronically at http://www.doc.gov/bridge

Available for a processing fee to U.S. Department of Energy

And its contractors in paper from

U.S. Department of Energy

Office of Scientific and Technical Information

P.O. Box 62

Oak Ridge, TN 37831-0062

Telephone: (865) 576-8401

Facsimile: (865) 576-5728

E-mail: reports@adonis.osti.gov

Available for the sale to the public from

U.S. Department of Commerce

National Technical Information Service

5285 Port Royal Road

Springfield, VA 22161

Telephone: (800) 553-6847

Facsimile: (703) 605-6900

E-mail: orders@ntis.fedworld.gov

Online ordering: http://www.ntis.gov/ordering.htm

OR

Lawrence Livermore National Laboratory

Technical Information Department's Digital Library

http://www.llnl.gov/tid/Library.html 


\title{
Demonstration of an
}

\section{Electronic Gamma-Ray Spectrum Synthesizer*}

\author{
S. John Luke, LLNL
}

\section{Goal of the Demonstration}

The goal of this demonstration was to show that it is possible to generate electronic signals that can accurately mimic the signals that are produced by a high-purity germanium (HPGe) gamma-ray detector. As an example of this fidelity, we decided to show that it was possible to perform a complex, multiplet-resolution analysis of a portion of the spectrum acquired from the gamma-ray spectrum synthesizer. We further showed that the results of this analysis were consistent with what would be obtained from a spectrum acquired from a real plutonium source and a real HPGe detector.

The gamma-ray synthesizer used in the JRC Ispra demonstration was our first laboratory prototype. In this version of the synthesizer we produced signals that mimicked the output of an HPGe detector preamplifier. Although not shown at Ispra, we have also demonstrated that we can produce signals that mimic the signals produced in the detector itself.

\section{Production of the electronically synthesized HPGe gamma-ray spectra}

Production of electronically synthesized HPGe gamma-ray spectra proceeded in two phases. In the first phase, a library of computed waveforms was computed that represented the pulse train from gamma-ray interactions in an HPGe detector from a plutonium source. The second phase accesses the library to generate a simulated detector output.

Phase 1: computing and recording a pulse train library. This phase consists of four steps.

1. We generated the detailed gamma-ray source term for a specific plutonium isotopic mixture. For this demonstration we assumed a weapons-grade plutonium source with a ${ }^{240} \mathrm{Pu}$ to ${ }^{239} \mathrm{Pu}$ ratio of approximately 0.06 . In addition, the other isotopes associated with weapons-grade plutonium $\left({ }^{236} \mathrm{Pu},{ }^{238} \mathrm{Pu},{ }^{241} \mathrm{Pu}\right.$, and ${ }^{242} \mathrm{Pu}$ ) were included in this calculation. This was accomplished by using the heavy-element gamma-ray source term code GamGen'.

2. This source term description was used as part of the input to a radiation transport calculation using the MCNP code ${ }^{2}$. In the MCNP model we assumed a 1-kg sphere of plutonium placed at meter from the face of an HPGe detector. The MCNP model followed each of the gamma rays to the surface of the germanium detector. The fourvectors of the gamma rays at the surface of the detector were recorded.

\footnotetext{
* This work was performed under the auspices of the U. S. Department of Energy by the University of California, Lawrence Livermore National Laboratory under Contract No. W-7405-Eng-48.
} 
3. These gamma-ray four-vectors were then used as input to the GEANT ${ }^{3}$ code from CERN to computationally transport the gamma rays and their induced charge carrier pairs in an applied electric field until all of their energy was deposited. At every interaction point the position of the interaction was recorded, as was the amount of energy deposited at that point.

1. The position of the interaction point and the energy deposition was used to generate a waveform ${ }^{4}$. This waveform is detector-dependent and, for the JRC Ispra demonstration, was tuned to an HPGe detector of $50 \%$ relative efficiency. The waveforms were digitized into 128 contiguous time bins of $15 \mathrm{~ns}$ width, producing a pulse duration of $1.9 \mu \mathrm{s}$. These waveforms are stored on disk for later use.

\section{Phase 2: Accessing the library to simulate a detector output}

1. The digitized waveforms on disk were then used to generate an electronic waveform using an arbitrary waveform generator. For this purpose we used a model AWG1000 arbitrary waveform generator from the Chase Scientific Company ${ }^{5}$.

2. The signals from the waveform generator were fed directly into a commercial multichannel analyzer, which generated the simulated plutonium pulse-height distributions.

\section{Experimental Results}

The results using the gamma-ray synthesizer were quite satisfactory. Pulse-height distributions produced by the synthesizer were analyzed using the $\mathrm{Pu}-600$ software $^{6}$ to determine the ${ }^{240} \mathrm{Pu}$ to ${ }^{239} \mathrm{Pu}$ ratios and produced results that were consistent within measurement uncertainties with the isotopic ratio that was used to generate the pulse height distribution. The errors in the analysis were due mainly to the limited number of waveforms that were generated (only 46,000 waveforms were available in time for the JRC Ispra demonstration).

\section{Conclusions}

We gave shown that an electronic gamma-ray synthesizer can be made based on first principles calculations. The results, in fact, exceeded our expectations. We have concluded that a larger number of waveforms are necessary to recreate the features of the continuum at higher energies. We also determined that more work is necessary to insure the fidelity of the spectrum at low-energies.

\section{References}

1. T.B. Gosnell, Automated calculation of photon source emission from arbitrary mixtures of naturally radioactive heavy nuclides, Nucl. Instr. And Meth. A299 (1990) 682 ,

2. http://www-xdiv.lanl.gov/XCI/PROJECTS/MCNP/. Los Alamos National Laboratory, Los Alamos, NM,

3. http://wwwinfo.cern.ch/asd/geant/, European Organization for Nuclear Research, Geneva. 
4. D.A. Beckedahl, Private communication, Lawrence Livermore National Laboratory, Livermore, CA.

5. http://www.chase2000.com/, Chase Scientific Company, Aptos, CA.

6. S.J. Luke, G.K. White, D.E. Archer, J.K. Wolford Jr, and T.B. Gosnell, Verification of the presence of weapons-quality plutonium in sealed storage containers for the Trilateral Initiative Demonstration, Lawrence Livermore National Laboratory, Livermore, CA, UCRL-JC-145918, IAEA-SM-367/17/08 (October 2001). 